\title{
Erosão em sistema plantio direto: Influência do comprimento de rampa e da direção de semeadura ${ }^{1}$
}

\author{
Renato L. e Silva ${ }^{2} \&$ Isabella C. De Maria ${ }^{2}$
}

\begin{abstract}
RESUMO
0 sistema plantio direto (SPD) é considerado o mais eficiente para controle da erosão em áreas de culturas anuais; entretanto, problemas de erosão com a formação de sulcos e ravinas em áreas de SPD, vêm sendo observados, sugerindo que práticas mecânicas, como operações em contorno e terraceamento, são imprescindíveis para o controle da erosão. 0 objetivo deste estudo foi determinar se o SPD permite a semeadura no sentido do declive e espaçamentos entre terraços maiores que os atualmente recomendados. 0 experimento foi realizado em um Latossolo Vermelho Distroférrico típico, de textura argilosa, com 6\% de declividade média, sob SPD há 6 anos, com as culturas de aveia preta e de milho, em parcelas com coletores de terra e de água perdidos por erosão, em dois ensaios: um com três comprimentos de rampa (25, 50 e $75 \mathrm{~m}$ ) e o outro com duas direções de semeadura (morro abaixo e em contorno) e dois comprimentos de rampa (50 e $75 \mathrm{~m}$ ). Não houve produção de sedimentos no SPD. As perdas de água foram reduzidas em comprimentos de rampa de até $75 \mathrm{~m}$ e não foram influenciadas pela direção de semeadura. A distância entre terraços pode ser ampliada no SPD para o solo e o declive estudados.
\end{abstract}

Palavras-chave: escoamento superficial, perdas de terra, semeadura direta, terraceamento

\section{Erosion in no-tillage system: Influence of ramp length and seeding direction}

\begin{abstract}
No-tillage system is considered the most efficient system for erosion control in annual crop plantations. However, problems of erosion as development of rills and ravines under no-tillage have been observed, suggesting that mechanical practices, such as contouring and terraces are required for erosion control. The objective of this study was to determine if no-tillage system allows seeding direction following dow $\mathrm{n}$ slope and ramp length larger than the currently recommended. The experiment was conducted in a clayey 0 xissol with a mean slope of $6 \%$ under no-tillage system for 6 years, cultivated with black oat and corn, in runoff plots with soil and water collector system. Two trials were conducted: one with three ramp lengths (25, 50 e $75 \mathrm{~m})$ and other with two seeding direction (in contour and following down slope) and two ramp lengths $(50$ e $75 \mathrm{~m})$. There was no sediment production under no-tillage system. Water losses were reduced in ramp length up to $75 \mathrm{~m}$ and were not influenced by seeding direction. The distance between terraces can be enlarged under no-tillage system for soil and slope studied.
\end{abstract}

Key words: no-tillage system, runoff, seeding direction, soil loss, terracing 


\section{INTRODUÇÃO}

Em sua maior extensão, a erosão do solo é ocasionada pela ação da água das chuvas e tem sido, nas condições de agricultura intensiva do Estado de São Paulo, um dos principais fatores de depauperamento acelerado da fertilidade do solo (Panachuki et al., 2006). As chuvas, quando não controladas convenientemente, desagregam o solo, arrastando quantidades consideráveis de sais minerais e matéria orgânica, agentes essenciais à sua fertilidade. Tal arrastamento, que se acentua com o aumento da declividade do terreno, poderá ocasionar, em certos tipos de solo, estragos irreparáveis, não só quanto à fertilidade mas também em relação à própria conformação do terreno.

O sistema plantio direto (SPD) é um sistema de manejo conservacionista constituído de práticas que envolvem, necessariamente, rotação de culturas, mobilização do solo exclusivamente na linha de semeadura e cobertura permanente do solo (Cassol et al., 2007). Trata-se de um conjunto de técnicas que revolucionaram a agricultura brasileira, pois resultam em aumentos na produtividade das principais culturas produtoras de grãos e na preservação e melhoria da capacidade produtiva do solo (Salton et al., 1998), pela redução da erosão, reciclagem de nutrientes, atividade biológica e manejo de resíduos culturais (Ceretta et al., 2002; Franchini et al., 2003).

A erosão é muito menor quando o sistema de manejo do solo é o SPD. Esta é, aliás, a primeira motivação para a adoção do sistema: menor ocorrência de perdas de terra, água e nutrientes por erosão em relação aos sistemas convencionais (arados ou grades) de preparo do solo (De Maria, 1999). Resultados obtidos por vários autores em ensaios comparando as perdas por erosão entre diferentes sistemas de manejo do solo, mostram que, em média, o SPD reduz as perdas de solo e de água em 84 e 58,7\%, respectivamente, em relação aos preparos convencionais (Schick et al., 2000; Leite et al., 2004; Bertol et al., 2007).

A eficiência do SPD no controle das perdas por erosão se deve ao não-revolvimento do solo e à cobertura morta que amortece o impacto das gotas de chuva, elimina o encrostamento superficial e mantém a capilaridade do solo, aumentando a infiltração e, consequentemente, reduzindo a enxurrada (Cogo et al., 1984; Bertol et al., 1997; Seganfredo et al., 1997). Essas características, juntamente com a rotação de culturas no SPD, proporcionam também uma melhoria das condições químicas, físicas e biológicas do solo (Silva et al., 2000).

Tal redução da erosão com o uso do SPD, porém, tem induzido, erroneamente, os produtores a eliminarem, das áreas de cultivo, os terraços e outras práticas conservacionistas de suporte, como a semeadura em contorno (Cogo et al., 2007; Denardin et al., 2008). O referido procedimento se baseia na idéia de que, com o SPD, a erosão e o escoamento superficial serão totalmente controlados nas lavouras agrícolas, dispensando qualquer outra prática adicional (Cogo et al., 2007). Poder-se-ia, desta forma, incorporar a área ocupada pelos terraços para cultivo, reduzir as manobras e aumentar a eficiência de operações mecanizadas (De Maria, 1999). Em decorrência, o terraceamento passou a ser considerado desnecessário e indiscriminadamente desfeito, levando ao abandono da semeadura em contorno e à adoção da semeadura paralela ao maior comprimento da gleba, independentemente do sentido do declive (Denardin et al., 2008). Apenas recentemente estudos sobre o efeito da direção da semeadura no SPD estão sendo realizados, como o de Cogo et al. (2007) que mostram reduções de 74 e $26 \%$ nas perdas de solo e de água a favor da semeadura em contorno.

O não-revolvimento do solo no SPD, aliado ao tráfego de máquinas, provoca compactação da camada superficial com aumento da densidade do solo e redução da porosidade total e dos macroporos (Bertol et al., 2004; Tormena et al., 2004; Garcia \& Righes, 2008). Essas alterações, associadas à reduzida rugosidade superficial, podem ser desfavoráveis à infiltração de água (Camara \& Klein, 2005), produzindo grandes enxurradas, especialmente sob certas situações, tais como solos de alta erodibilidade, umidade antecedente e precipitações elevadas, longos comprimentos de rampa e/ou maiores inclinações do terreno e ausência de práticas conservacionistas de suporte, que podem ocasionar perdas de solo elevadas no SPD (Morais \& Cogo, 2001; Bertol et al., 2007). Referido comportamento foi observado por Eltz et al. (1984), Cogo et al. (2003) e Mello et al. (2003), que verificaram eficiência menor do SPD no controle da enxurrada $(21,7 \%)$ do que no controle das perdas de solo $(76,8 \%)$ em relação ao sistema convencional.

Esses resultados indicam a necessidade de se conter a enxurrada nas lavouras, mesmo que elas estejam sobre SPD (Bertol et al., 2007a; 2007b), aumentando a infiltração da água no solo (Eltz et al., 1984), pela implantação e/ou manutenção de práticas conservacionistas de suporte, como o terraceamento e a semeadura em contorno (Bertol et al., 2007a). Objetivou-se com este trabalho determinar se o SPD permite a semeadura no sentido do declive e espaçamentos entre terraços maiores que os atualmente recomendados para o controle das perdas de água e solo por erosão.

\section{Material e mÉtodos}

O experimento foi realizado na área dos sistemas coletores de erosão em culturas anuais do Centro Experimental Central do Instituto Agronômico, localizado na cidade de Campinas, SP. O clima da região, segundo a classificação de Köppen, é uma transição entre os tipos Cwa e Cfa (Rolim et al., 2007), definido como tropical de altitude com inverno seco e verão úmido, com precipitação média de $1.381 \mathrm{~mm}$ anuais e temperatura média anual de $21,7^{\circ} \mathrm{C}$. O solo do local é um Latossolo Vermelho Distroférrico típico (EMBRAPA, 2006) de textura argilosa, com 6\% de declividade média e suas características químicas e texturais na profundidade de 0,00 0,20 m, de acordo com as metodologias de Raij et al. (2001) e Camargo et al. (1986), são apresentadas na Tabela 1.

A área experimental vem sendo conduzida em SPD, desde 2002/2003, com semeadora-adubadora de discos duplos concêntricos e cultivo da rotação soja ou milho no verão e sorgo, aveia, chícharo ou triticale no outono/inverno. Antes da implantação do sistema a área foi preparada com uma escarificação, duas gradagens pesadas e uma gradagem niveladora. 
Tabela 1. Caracterização química e textural do Latossolo Vermelho Distroférrico típico, de textura argilosa na profundidade de $0,00-0,20 \mathrm{~m}$

\begin{tabular}{|c|c|c|c|c|c|c|c|c|c|c|c|c|}
\hline \multicolumn{10}{|c|}{ Características químicas } & \multicolumn{3}{|c|}{ Composição granulométrica } \\
\hline \multirow{2}{*}{$\begin{array}{c}\text { MO } \\
\left(\mathrm{g} \mathrm{dm}^{-3}\right)\end{array}$} & \multirow{2}{*}{$\mathrm{pH} \mathrm{CaCl}{ }_{2}$} & \multirow{2}{*}{$\begin{array}{c}P \\
\left(\mathrm{mg} \mathrm{dm}^{-3}\right)\end{array}$} & $\mathrm{K}$ & $\mathrm{Ca}$ & $\mathrm{Mg}$ & $\mathrm{H}+\mathrm{Al}$ & SB & CTC & \multirow{2}{*}{$\begin{array}{l}\text { V\% } \\
(\%)\end{array}$} & Areia total & Silte & Argila \\
\hline & & & \multicolumn{6}{|c|}{$\left(\mathrm{mmol}_{\mathrm{c}} \mathrm{dm}^{-3}\right)$} & & \multicolumn{3}{|c|}{ 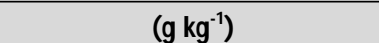 } \\
\hline 32 & 4,8 & 62,7 & 3,8 & 31,7 & 14,9 & 45,7 & 50,4 & 96,3 & 52,3 & 314 & 179 & 507 \\
\hline
\end{tabular}

De acordo com as recomendações de Lombardi Neto et al. (1994), o valor do espaçamento entre terraços para esse solo com culturas anuais, em sistema convencional, é de 26,6 m; para o SPD, elas indicam que o espaçamento entre terraços pode ser ampliado (43,2 m) em relação ao convencional, embora seus valores não tenham ainda sido testados no atual pacote tecnológico desse sistema, incluindo uma quantidade maior de palha em cobertura. Com base nessas informações foram estabelecidos dois ensaios para avaliar o efeito do comprimento do declive e da direção de semeadura nas perdas de solo e água por erosão em SPD. No Ensaio 1, a semeadura das culturas foi realizada em contorno (EC), em parcelas de $8 \mathrm{~m}$ de largura por 25,50 e $75 \mathrm{~m}$ de comprimento de rampa. No Ensaio 2, a semeadura das culturas foi executada morro abaixo (MA) e em contorno (EC), em parcelas de $25 \mathrm{~m}$ de largura por 50 e $75 \mathrm{~m}$ de comprimento de rampa.

As avaliações se iniciaram no dia 13/5/2008, com a semeadura da aveia preta (Avena strigosa Schreb), conforme as direções estabelecidas para os ensaios, no espaçamento $0,30 \mathrm{~m}$ entre linhas e com densidade de 60 sementes $\mathrm{m}^{-1}$, com adubação NPK 8-28-16 na base de $150 \mathrm{~kg} \mathrm{ha}^{-1}$. Após a semeadura da aveia preta foram refeitos os camalhões de terra delimitadores das parcelas dos ensaios que conduzem a enxurrada (água e sedimentos) até os tanques coletores. Durante o ciclo da aveia preta aplicou-se herbicida para o controle das plantas infestantes no dia 25/6/ 2008, adubação de cobertura no dia 2/7/2008 e aos 144 dias de cultivo executou-se a colheita mecanizada.

No período entre a colheita da aveia preta e a instalação da cultura de verão (pousio) foram realizadas, nos ensaios, uma passada de roçadora para melhorar a distribuição dos resíduos vegetais (palha) nas parcelas (14/10/2008), uma aplicação de herbicida para controle das plantas daninhas (11/11/2008) e de $2,5 \mathrm{Mg} \mathrm{ha}^{-1}$ de calcário em superfície para a correção da acidez do solo (19/11/2008).

A semeadura do milho (Zea mays L.) foi feita 6 dias após a calagem superficial, no espaçamento $0,90 \mathrm{~m}$ entre linhas e $0,17 \mathrm{~m}$ entre plantas, com adubação NPK 6-21-12 na dose de $300 \mathrm{~kg} \mathrm{ha}^{-1}$; a direção de semeadura foi igual à executada no estabelecimento da aveia preta, no outono/inverno de 2008, assim como a manutenção dos camalhões de terra das parcelas (9/12/2008).
Os tratos culturais realizados durante o ciclo do milho foram adubação de cobertura, no dia 22/12/2008, e capina manual, acima das soleiras coletoras de enxurrada das parcelas, nos dias 14 e 15/1/2009; a colheita mecanizada do milho dos ensaios foi efetuada 6 dias antes do término do período de avaliações do experimento (12/5/2009).

No final de cada parcela dos ensaios há um sistema para coleta de água e sedimentos arrastados por erosão, formado por uma soleira concentradora, que conduz a enxurrada até um primeiro tanque de decantação, e por dois conjuntos de um divisor e uma calha, que direcionam uma fração da enxurrada do primeiro tanque de decantação para o segundo e deste para o tanque de armazenamento, quando a capacidade dos mesmos é excedida (Bertoni \& Lombardi Neto, 2008). As perdas por erosão foram determinadas em intervalos de 24 h sempre após cada chuva que causou enxurrada, e os cálculos feitos conforme os procedimentos descritos por Bertoni (1949), sendo as perdas de solo expressas em $\mathrm{Mg} \mathrm{ha}^{-1} \mathrm{e}$ as perdas de água em $\mathrm{mm}$.

Paralelamente a essas medições foi feito o registro diário das chuvas ocorridas no período do experimento (13/5/2008 a 12/5/2009), com pluviógrafos modelo Hillman, instalados em uma estação pluviométrica próxima aos ensaios. Para as chuvas que causaram perdas por erosão (solo e/ou água) e foram maiores ou iguais a $10 \mathrm{~mm}$ ou apresentaram $6 \mathrm{~mm}$ ou mais precipitados em um período máximo de $15 \mathrm{~min}$ (Carvalho et al., 2004), foi calculado o índice de erosividade da chuva $\left(\mathrm{EI}_{30}\right)$, de acordo com Wischmeier \& Smith (1978). Somando os índices $\mathrm{EI}_{30}$ de todas as chuvas individuais e erosivas de cada mês, obteve-se a erosividade mensal e, consequentemente, a erosividade anual das chuvas.

Além das medições realizadas a campo foram calculadas também as seções transversais do canal dos terraços, necessárias para o controle da enxurrada.

O solo da área experimental apresenta propriedades físicas favoráveis à infiltração de água no seu perfil (Tabela 2), como grande profundidade, baixa razão textural entre horizontes e elevada porosidade e permeabilidade; desta forma, o tipo de terraço recomendado para o mesmo é o terraço em nível.

O dimensionamento da seção transversal do canal dos terraços em nível para as parcelas dos ensaios, foi feito de

Tabela 2. Valores médios e coeficiente de variação (CV\%) de atributos físicos do Latossolo Vermelho Distroférrico típico de textura argilosa

\begin{tabular}{|c|c|c|c|c|c|c|c|c|c|c|c|c|c|}
\hline & \multirow{3}{*}{$\begin{array}{c}D_{s} \\
\left(\mathrm{Mg} \mathrm{m}^{3}\right)\end{array}$} & \multirow{3}{*}{ PT } & \multirow{2}{*}{ Mi } & \multirow{3}{*}{$\mathrm{Ma}$} & \multirow{2}{*}{ Inf } & \multirow{2}{*}{$\mathbf{K}_{\theta}$} & \multirow{3}{*}{$\begin{array}{l}\text { DMP } \\
(\mathrm{mm})\end{array}$} & \multicolumn{4}{|c|}{$\mathbf{R P}$} & \multicolumn{2}{|c|}{$\mathbf{U}$} \\
\hline & & & & & & & & $0,0-0,1 \mathrm{~m}$ & $0,1-0,2 \mathrm{~m}$ & $0,2-0,3 \mathrm{~m}$ & $0,3-0,4 \mathrm{~m}$ & $0-0,2 \mathrm{~m}$ & $0,2-0,4 \mathrm{~m}$ \\
\hline & & & $\left(m^{3} m^{-3}\right)$ & & \multicolumn{2}{|c|}{$\left(\mathrm{mm} \mathrm{h}^{-1}\right)$} & & \multicolumn{4}{|c|}{ (MPa) } & \multicolumn{2}{|c|}{$\left(g^{-1}\right)$} \\
\hline $\mathrm{n}$ & 63 & 63 & 63 & 63 & 87 & 87 & 21 & 87 & 87 & 87 & 87 & 7 & 7 \\
\hline Média & 1,3 & 0,5 & 0,4 & 0,1 & 198,8 & 45,8 & 1,08 & 3,13 & 4,07 & 3,86 & 3,22 & 0,226 & 0,227 \\
\hline $\mathrm{CV}(\%)$ & 5 & 6 & 6 & 20 & 55 & 54 & 19 & 61 & 57 & 42 & 25 & 36 & 36 \\
\hline
\end{tabular}

$\mathrm{n}=$ tamanho da amostra; $\mathrm{D}_{\mathrm{s}}=$ densidade do solo; PT = porosidade total; $\mathrm{Mi}=$ microporosidade; $\mathrm{Ma}=$ macroporosidade; Inf = infiltração de água; $\mathrm{K}_{\dot{\mathrm{e}}}=$ condutividade hidráulica saturada; $\mathrm{DMP}=$ diâmetro médio ponderado; RP = resistência do solo à penetração; $U$ = umidade gravimétrica 
acordo com a metodologia de Lombardi Neto et al. (1994). Os espaçamentos horizontais entre terraços $(\mathrm{EH})$ foram definidos como os comprimentos de rampa estabelecidos para cada parcela dos ensaios. O valor da chuva diária máxima (h) utilizada para Campinas, SP, foi de $105 \mathrm{~mm}$ para o período de retorno de 10 anos (Vieira et al., 1991). Para o coeficiente de enxurrada (c) utilizou-se o valor de $0,40\left(c_{t}\right)$, relativo a um solo do grupo hidrológico A, com declividade entre 5 e $10 \%$ e cobertura vegetal formada por cultivos (Lombardi Neto et al., 1994); utilizaramse, também, os valores máximos de coeficiente de enxurrada $\left(c_{d}\right)$ determinados por meio da relação entre as perdas diárias de água, em mm, de cada parcela dos ensaios e o volume diário das chuvas erosivas.

Devido à dificuldade de se encontrar uma área com características topográficas e de solo uniformes para o estabelecimento do experimento, em parcelas com sistema de coletores de enxurrada (solo e água), os tratamentos dos ensaios foram instalados sem repetições. As perdas de solo e água por erosão foram comparadas entre as parcelas de cada ensaio, para os ciclos da aveia preta e do milho, para o intervalo entre as duas culturas (pousio) e para o período total do experimento (13/5/2008 a 12/5/2009). Para este período foi realizada, também, análise de regressão entre as perdas de água medidas em cada parcela dos ensaios 1 e 2 e o índice de erosividade da chuva $\left(\mathrm{EI}_{30}\right)$.

\section{RESULTADOS E DISCUSSÃO}

Durante o experimento (13/5/2008 a 12/5/2009), ocorreram 111 chuvas, com precipitação total de $1.177,2 \mathrm{~mm}$; as chuvas se concentraram no ciclo do milho (68 chuvas), correspondendo a $63 \%$ da pluviosidade total. O número de chuvas e o volume total precipitado no ciclo da aveia preta e no período entre as duas culturas (pousio) foram bem próximos (23 chuvas e 202,5 mm; 20 chuvas e 232,7 $\mathrm{mm}$ respectivamente), mas com uma concentração maior no período apenas com palha na superfície, que compreendeu os meses de outubro e novembro de 2008 (Figura 1).

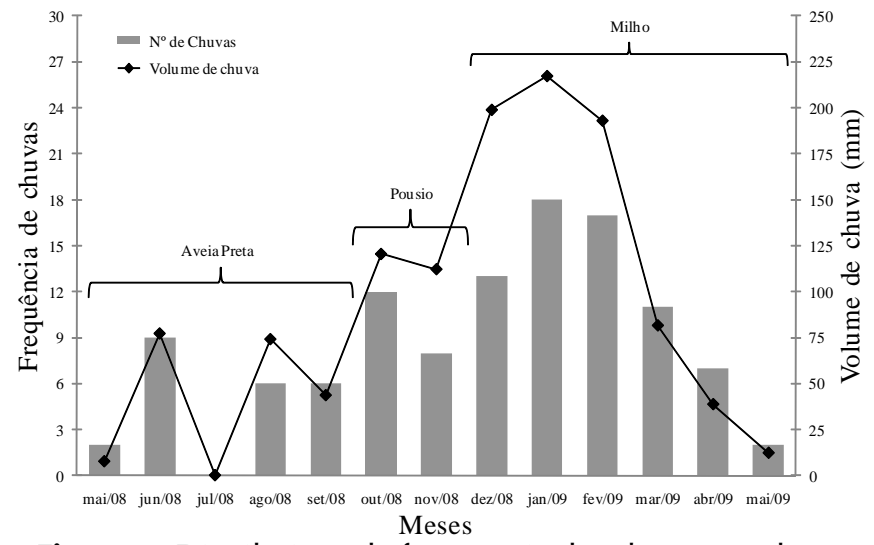

Figura 1. Distribuição de frequência das chuvas e volume mensal de chuvas no período de 13/5/2008 a 12/5/2009

No Ensaio 1 observou-se a formação de enxurrada nas parcelas em 41 chuvas, sendo 34 consideradas erosivas e responsáveis por quase dois terços $(64,5 \%)$ da precipitação total do período (Tabela 3). Essas 34 chuvas apresentaram um volume médio de $22,3 \mathrm{~mm}$, com variação de 8,8 a 40,2 mm, desvio padrão de $8,6 \mathrm{~mm}$ e coeficiente de variação de $38,6 \%$.

O ciclo do milho (2008/2009) apresentou a maior ocorrência de chuvas erosivas ( 27 chuvas), com $77,8 \%$ concentradas nos meses de dezembro de 2008 e janeiro e fevereiro de 2009 (Tabela 3); essas chuvas totalizaram 582,5 mm, com precipitação média de 21,6 mm, desvio padrão de $8,7 \mathrm{~mm}$ e coeficiente de variação de $40,3 \%$. No ciclo da aveia preta (outono/inverno de 2008) e no pousio ocorreram apenas $20,6 \%$ das chuvas erosivas, com precipitação total de $176,3 \mathrm{~mm}$; entretanto, observou-se maior volume médio das chuvas erosivas $(25,2 \mathrm{~mm})$, com pluviosidade variando de 16,2 a $38,7 \mathrm{~mm}$, desvio padrão de 8,3 mm e coeficiente de variação de $32,9 \%$.

$\mathrm{O}$ valor absoluto calculado do índice $\mathrm{EI}_{30}$ para as chuvas erosivas do Ensaio 1, no período do experimento, foi de $3.910 \mathrm{MJ} \mathrm{mm} \mathrm{ha}{ }^{-1} \mathrm{~h}^{-1}$ (Tabela 3). Observou-se uma concentração desse índice na safra de milho 2008/2009, sendo responsável por $77,5 \%$ da erosividade total; a maior ocorrência

Tabela 3. Volume e frequência de chuvas, índice de erosividade da chuva $\left(\mathrm{E}_{30}\right)$ e perdas de água por erosão, medidos nas parcelas do Ensaio 1

\begin{tabular}{|c|c|c|c|c|c|c|c|c|c|}
\hline \multirow{3}{*}{ Mês/Ano* } & \multicolumn{2}{|c|}{ Chuvas erosivas } & \multirow{3}{*}{$\begin{array}{c}\mathrm{EI}_{30} \\
\text { (MJ } \mathrm{mm} \mathrm{ha}^{-1} \mathrm{~h}^{-1} \text { ) }\end{array}$} & \multicolumn{6}{|c|}{ Perdas de água por erosão } \\
\hline & \multirow{2}{*}{$\begin{array}{l}\text { Volume } \\
\text { (mm) }\end{array}$} & \multirow{2}{*}{$\begin{array}{c}\text { Frequência } \\
\text { - }\end{array}$} & & \multicolumn{2}{|c|}{$25 \mathrm{~m}$} & \multicolumn{2}{|c|}{$50 \mathrm{~m}$} & \multicolumn{2}{|c|}{$75 \mathrm{~m}$} \\
\hline & & & & (L) & $(\mathrm{mm})$ & (L) & $(\mathrm{mm})$ & (L) & (mm) \\
\hline jun/08 & 58,6 & 2 & 236,6 & 374 & 1,87 & 369 & 0,92 & 410 & 0,68 \\
\hline ago/08 & 16,2 & 1 & 21,7 & 0 & 0 & 10 & 0,02 & 0 & 0 \\
\hline Total Aveia Preta & 74,8 & 3 & 258,3 & 374 & 1,87 & 379 & 0,95 & 410 & 0,68 \\
\hline out/08 & 58,2 & 2 & 318,1 & 180 & 0,90 & 202 & 0,51 & 227 & 0,38 \\
\hline nov/08 & 43,3 & 2 & 303,1 & 486 & 2,43 & 462 & 1,15 & 652 & 1,09 \\
\hline Total Pousio & 101,5 & 4 & 621,2 & 666 & 3,33 & 664 & 1,66 & 880 & 1,47 \\
\hline $\mathrm{dez} / 08$ & 172,6 & 7 & 847,2 & 1811 & 9,05 & 1791 & 4,48 & 2037 & 3,39 \\
\hline jan/09 & 160,5 & 8 & 792,0 & 1481 & 7,40 & 1253 & 3,13 & 1388 & 2,31 \\
\hline fev/09 & 149,9 & 6 & 1081,8 & 1408 & 7,04 & 1640 & 4,10 & 1966 & 3,28 \\
\hline $\mathrm{mar} / 09$ & 71,7 & 4 & 248,4 & 416 & 2,08 & 360 & 0,90 & 320 & 0,53 \\
\hline abr/09 & 19,0 & 1 & 24,3 & 50 & 0,25 & 53 & 0,13 & 8 & 0,01 \\
\hline mai/09 & 8,8 & 1 & 36,8 & 124 & 0,62 & 127 & 0,32 & 121 & 0,20 \\
\hline Total Milho & 582,5 & 27 & 3030,5 & 5289 & 26,45 & 5225 & 13,06 & 5839 & 9,73 \\
\hline TOTAL & 758,8 & 34 & 3910,0 & 6329 & 31,65 & 6267 & 15,67 & 7129 & 11,88 \\
\hline
\end{tabular}


de chuvas intensas e de grande capacidade erosiva foi observada nos meses de dezembro de 2008, janeiro e fevereiro de 2009 (847,2; 792,0 e 1.081,8 MJ mm ha $\mathrm{h}^{-1}$, respectivamente). Apesar da elevada erosividade da chuva concentrada nesses meses, não se observou produção de sedimentos nas parcelas do Ensaio 1, em função, provavelmente, da proteção da superfície do solo pela cobertura vegetal, formada pelo sistema plantio direto, que dissipa a energia cinética das gotas de chuva, evitando a desagregação das partículas de solo e, em contrapartida, o transporte de sedimentos na enxurrada (Cogo et al., 1984). Além disso, a ampliação dos comprimentos de rampa nessa condição de baixa declividade não aumentou a energia cisalhante da enxurrada, a ponto de causar a remoção dos resíduos vegetais da superfície e o aumento na taxa de erosão do solo nas parcelas, semelhante ao observado por Foster et al. (1982).

Analisando as perdas de água do Ensaio 1 durante o período do experimento (Tabela 3 ) verificou-se que os volumes totais escoados nas parcelas de 25 e $50 \mathrm{~m}$ de comprimento de rampa foram próximos (6.329 e 6.267 L respectivamente) e na parcela de $75 \mathrm{~m}$ o volume total de enxurrada observado foi de $7.129 \mathrm{~L}$; apesar do maior volume de água escoado, essa parcela apresentou a menor perda total de água por unidade de área, entre as parcelas do Ensaio 1 (11,88 mm). As reduções nas perdas de água por unidade de área em sistema plantio direto semeado em contorno, com o comprimento de rampa de $75 \mathrm{~m}$, foram de 50,5 e 24,2\% em relação às parcelas de 25 e $50 \mathrm{~m}$ de comprimento de lançante, respectivamente, comportamento este observado tanto no ciclo das culturas (aveia preta e milho) quanto no período de pousio. Tais reduções nas perdas de água por unidade de área, são devidas à maior possibilidade que a água tem de se infiltrar ou evaporar, em razão do aumento do percurso percorrido pela enxurrada na superfície do solo (Bertoni \& Lombardi Neto, 2008).

A Figura 2 apresenta os resultados das perdas de água por unidade de área, em função dos valores do índice de erosividade da chuva correspondente $\left(\mathrm{EI}_{30}\right)$. A relação entre o $\mathrm{EI}_{30}$ e as perdas de água segue um modelo quadrático, para os três comprimentos de rampa estudados, com coeficientes de regressão entre 0,68 e 0,72 significativos, demonstrando o efeito do aumento do comprimento de rampa na redução do volume escoado por unidade de área.

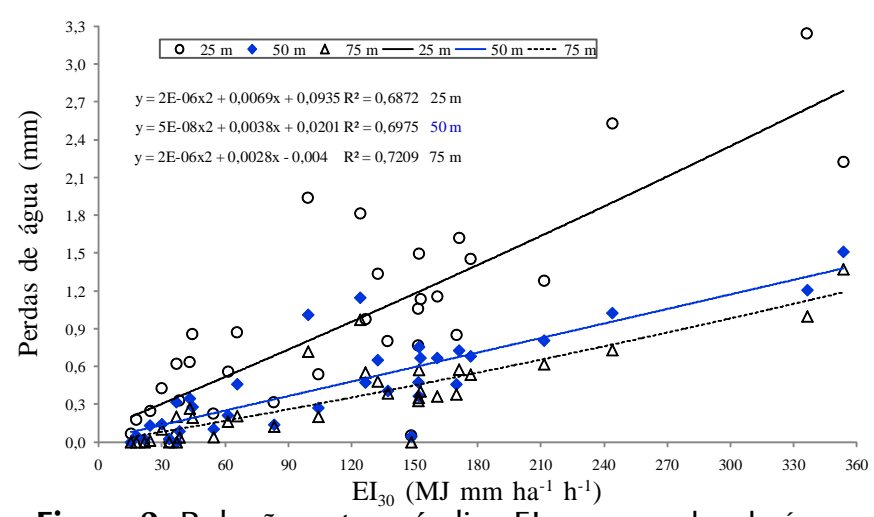

Figura 2. Relação entre o índice $\mathrm{EI}_{30}$ e as perdas de água por unidade de área, de 34 chuvas erosivas medidas nas parcelas do Ensaio 1

Das 111 chuvas ocorridas durante o experimento, apenas 30 causaram escoamento superficial nas parcelas do Ensaio 2, sendo 28 consideradas erosivas, as quais representaram $55 \%$ (647,3 mm) do volume total precipitado entre 13/5/2008 e 12/ $5 / 2009$ (Tabela 4), caracterizando-se por volume médio de 23,1 mm, desvio padrão de $8,3 \mathrm{~mm}$ e coeficiente de variação de $36 \%$.

No Ensaio 2 as chuvas erosivas ocorreram em maior quantidade (23 chuvas) no ciclo do milho (Tabela 4), sendo o volume total dessas chuvas de $525,9 \mathrm{~mm}$, com precipitação média de 22,9 mm, desvio padrão de $8,8 \mathrm{~mm}$ e coeficiente de variação de $38,4 \%$. No período do ciclo da aveia preta houve apenas duas chuvas erosivas, que se caracterizaram pela maior média de precipitação entre os ciclos desse ensaio (29,3 mm), desvio padrão de $6,4 \mathrm{~mm}$ e coeficiente de variação de $21,8 \%$. No período de pousio observou-se um volume de chuva maior que no ciclo da aveia preta, com média de precipitação das três chuvas erosivas igual de 20,9 mm e coeficiente de variação de $16,3 \%$.

Tabela 4. Volume e frequência de chuvas, índice de erosividade da chuva $\left(\mathrm{EI}_{30}\right)$ e perdas de água por erosão, medidos nas parcelas do Ensaio 2

\begin{tabular}{|c|c|c|c|c|c|c|c|c|c|c|c|}
\hline \multirow{3}{*}{ Mês/Ano* } & \multicolumn{2}{|c|}{ Chuvas erosivas } & \multirow{3}{*}{$\begin{array}{c}\mathrm{EI}_{30} \\
\left(\mathrm{MJ} \mathrm{mm} \mathrm{ha}^{-1} h^{-1} \text { ) }\right.\end{array}$} & \multicolumn{8}{|c|}{ Perdas de água por erosão } \\
\hline & \multirow{2}{*}{$\begin{array}{c}\text { Volume } \\
\text { (mm) }\end{array}$} & \multirow{2}{*}{$\begin{array}{c}\text { Frequência } \\
\text { - }\end{array}$} & & \multicolumn{2}{|c|}{$M A-50 \mathrm{~m}$} & \multicolumn{2}{|c|}{ MA - $75 \mathrm{~m}$} & \multicolumn{2}{|c|}{ EC $-50 \mathrm{~m}$} & \multicolumn{2}{|c|}{$E C-75 \mathrm{~m}$} \\
\hline & & & & (L) & $(\mathrm{mm})$ & (L) & $(\mathrm{mm})$ & (L) & $(\mathrm{mm})$ & (L) & $(\mathrm{mm})$ \\
\hline $\begin{array}{l}\text { jun/08 } \\
\text { Total Aveia Preta }\end{array}$ & $\begin{array}{l}58,6 \\
58,6\end{array}$ & $\begin{array}{l}2 \\
2\end{array}$ & $\begin{array}{l}236,6 \\
236,6\end{array}$ & $\begin{array}{l}865 \\
865\end{array}$ & $\begin{array}{l}0,69 \\
0,69\end{array}$ & $\begin{array}{l}634 \\
634\end{array}$ & $\begin{array}{l}0,34 \\
0,34\end{array}$ & $\begin{array}{l}715 \\
715\end{array}$ & $\begin{array}{l}0,57 \\
0,57\end{array}$ & $\begin{array}{l}612 \\
612\end{array}$ & $\begin{array}{l}0,33 \\
0,33\end{array}$ \\
\hline $\begin{array}{c}\text { out/08 } \\
\text { nov/08 } \\
\text { Total Pousio }\end{array}$ & $\begin{array}{l}19,5 \\
43,3 \\
62,8\end{array}$ & $\begin{array}{l}1 \\
2 \\
3\end{array}$ & $\begin{array}{l}169,7 \\
303,1 \\
472,8\end{array}$ & $\begin{array}{r}518 \\
1049 \\
1567\end{array}$ & $\begin{array}{l}0,41 \\
0,84 \\
1,25\end{array}$ & $\begin{array}{l}204 \\
660 \\
864\end{array}$ & $\begin{array}{l}0,11 \\
0,35 \\
0,46\end{array}$ & $\begin{array}{r}323 \\
963 \\
1286\end{array}$ & $\begin{array}{l}0,26 \\
0,77 \\
1,03\end{array}$ & $\begin{array}{r}322 \\
755 \\
1077\end{array}$ & $\begin{array}{l}0,17 \\
0,40 \\
0,57\end{array}$ \\
\hline $\begin{array}{c}\text { dez/08 } \\
\text { jan/09 } \\
\text { fev/09 } \\
\text { mar/09 } \\
\text { abr/09 } \\
\text { mai/09 } \\
\text { Total Milho }\end{array}$ & $\begin{array}{r}157,0 \\
147,5 \\
136,9 \\
56,7 \\
19,0 \\
8,8 \\
525,9\end{array}$ & $\begin{array}{r}6 \\
7 \\
5 \\
3 \\
1 \\
1 \\
23\end{array}$ & $\begin{array}{r}810,2 \\
776,8 \\
1048,4 \\
210,2 \\
24,3 \\
36,8 \\
2906,7 \\
\end{array}$ & $\begin{array}{r}3426 \\
1789 \\
2461 \\
303 \\
0 \\
112 \\
8092 \\
\end{array}$ & $\begin{array}{l}2,74 \\
1,43 \\
1,97 \\
0,24 \\
0 \\
0,09 \\
6,47 \\
\end{array}$ & $\begin{array}{r}2534 \\
1606 \\
2521 \\
270 \\
35 \\
26 \\
6991 \\
\end{array}$ & $\begin{array}{l}1,35 \\
0,86 \\
1,34 \\
0,14 \\
0,02 \\
0,01 \\
3,73\end{array}$ & $\begin{array}{r}3256 \\
1887 \\
2293 \\
175 \\
0 \\
88 \\
7699 \\
\end{array}$ & $\begin{array}{l}2,61 \\
1,51 \\
1,83 \\
0,14 \\
0 \\
0,07 \\
6,16 \\
\end{array}$ & $\begin{array}{r}2895 \\
1959 \\
2426 \\
253 \\
174 \\
68 \\
7775 \\
\end{array}$ & $\begin{array}{l}1,54 \\
1,04 \\
1,29 \\
0,13 \\
0,09 \\
0,04 \\
4,15\end{array}$ \\
\hline TOTAL & 647,3 & 28 & 3616,1 & 10523 & 8,42 & 8489 & 4,53 & 9700 & 7,76 & 9464 & 5,05 \\
\hline
\end{tabular}

* Nos meses de mai/08, jul/08, ago/08 e set/08 não ocorreram chuvas erosivas 
Devido à menor ocorrência de chuvas erosivas (Tabela 4), o Ensaio 2 apresentou, no período total do experimento, um valor absoluto do índice $\mathrm{EI}_{30}$ inferior ao obtido no Ensaio 1 (3.616,1 MJ mm ha-1 $\mathrm{h}^{-1}$ ). Apesar disso, o período com a maior participaçãonesse índice foi ociclodo milho $\left(2.906,7 \mathrm{MJ} \mathrm{mm} \mathrm{ha}^{-1} \mathrm{~h}^{-1}\right)$, tal como o observado no Ensaio 1, com destaque para os meses de dezembro de 2008, janeiro e fevereiro de 2009 que representaram, juntos, $72,9 \%$ do valor absoluto do mesmo. Com essas condições de erosividade da chuva não se constataram perdas de solo nas parcelas do Ensaio 2.

Como no Ensaio 1, as perdas de água no Ensaio 2 se concentraram nos meses de maior ocorrência de chuvas erosivas. Os volumes totais de enxurrada foram semelhantes entre as parcelas de 50 e $75 \mathrm{~m}$ de comprimento de rampa, semeadas em contorno ( 9.700 e $9.464 \mathrm{~L}$ respectivamente) mas, quando a semeadura foi executada morro abaixo, verificou-se uma diferença de $2.034 \mathrm{~L}$ entre os dois comprimentos de declive estudados (Tabela 4). Apesar da variação no volume total de água escoada notou-se, nesse ensaio, redução nas perdas de água por unidade de área, com aumento do comprimento de rampa, independentemente da direção em que foi feita a semeadura. Na semeadura morro abaixo, o aumento do comprimento de rampa, de 50 para $75 \mathrm{~m}$, diminuiu as perdas totais de água por unidade de área em 46,2\%. Já na semeadura em contorno com o aumento do comprimento de rampa de 50 para $75 \mathrm{~m}$, as perdas de água reduziram de 7,76 para $5,05 \mathrm{~mm}$ $(34,9 \%)$, efeito verificado nas três condições de cobertura utilizadas no experimento: no ciclo da aveia preta, no período de pousio e no ciclo do milho.

Ao se analisar o efeito da mudança da direção de semeadura nas perdas de água verificou-se que, para o comprimento de rampa de $50 \mathrm{~m}$, a semeadura em contorno teve um volume de enxurrada total por unidade de área 7,8\% menor que a semeadura realizada morro abaixo (Tabela 4). O mesmo comportamento ocorreu nas três condições de cultivo do experimento, com as maiores reduções nas perdas de água observadas nos períodos com a menor ocorrência de chuvas erosivas (ciclo da aveia preta e pousio); efeito semelhante foi obtido por Andrade et al. (1999), variando apenas quanto ao percentual de redução de enxurrada observado (40\%), e também por Albuquerque et al. (2002), Carvalhoet al. (2009), em sistema convencional. A menor perda de água na semeadura em contorno decorre da formação de pequenos camalhões transversais ao sentido do declive na superfície do solo, que atuam como barreiras físicas, retendo a água da chuva, aumentando seu tempo de permanência, permitindo maior infiltração e menor escoamento superficial.

Entretanto, as perdas de água no comprimento de rampa de $75 \mathrm{~m}$ se comportaram de forma diferente entre os ciclos culturais estudados e em relação ao total observado nas parcelas de $50 \mathrm{~m}$ de comprimento de rampa (Tabela 4). No ciclo da aveia preta as perdas de água por unidade de área foram muito próximas entre as direções de semeadura mas com pequena redução a favor da orientação dos sulcos em contorno $(2,9 \%)$. No período de pousio e no ciclo do milho, as perdas de água por unidade de área na semeadura em contorno foram 23,9 e $11,3 \%$ maiores que as da semeadura morro abaixo, respectivamente. No período completo do experimento as perdas de água por unidade de área na semeadura em contorno foram $11,5 \%$ superiores às perdas na semeadura executada morro abaixo, devido principalmente aos resultados obtidos no ciclo de maior ocorrência de chuvas erosivas (milho). Esses resultados diferem dos obtidos por Cogo et al. (2007), que verificaram redução nas perdas de água na semeadura em contorno, em relação ao morro abaixo, em Argissolo Vermelho distrófico típico, de textura franco arenosa, cultivado com milho em SPD.

A diferença nas perdas de água a favor da direção morro abaixo no comprimento de $75 \mathrm{~m}$, contrariando os resultados obtidos por outros autores, e também a pequena diferença a favor da direção em contorno no comprimento de $50 \mathrm{~m}$, podem ter, como causas, fatores como tipo de solo, declividade, implementos utilizados, clima e, especialmente, o sistema de manejo. Neste ensaio, o SPD com grande quantidade de palha na superfície em um solo com alta capacidade de infiltração e relativamente baixa declividade, pode ter atenuado os efeitos da direção de semeadura em virtude da palha constituir um obstáculo maior na superfície do que os pequenos camalhões feitos pelos discos da semeadora.

Na Figura 3 se apresentam os resultados das perdas de água por unidade de área, em função dos valores do índice de erosividade da chuva correspondente $\left(\mathrm{EI}_{30}\right)$ para o Ensaio 2; a relação segue um modelo de $2^{\circ}$ grau para os quatro tratamentos estudados, com coeficientes de regressão entre 0,73 e 0,82 significativos demonstrando, mais uma vez, o efeito do aumento do comprimento de rampa na redução do volume escoado por unidade de área, porém para cada comprimento de rampa não se observou diferença entre as curvas de regressão das direções de semeadura.

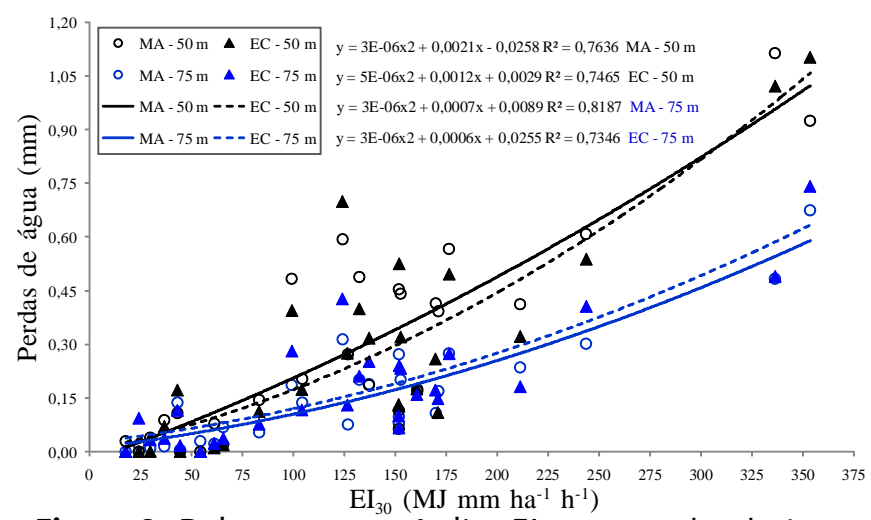

Figura 3. Relação entre o índice $\mathrm{EI}_{30}$ e as perdas de água por unidade de área, de 28 chuvas erosivas medidas nas parcelas do Ensaio 2

As seções transversais do canal dos terraços $\left(\mathrm{At}_{\mathrm{t}} \mathrm{e} \mathrm{At}_{\mathrm{d}}\right)$ das parcelas calculadas para as condições do experimento, apresentaram diferenças em função dos valores do coeficiente de enxurrada (c) utilizados. As dimensões dessas estruturas foram, na média dos Ensaios 1 e 2, iguais a 2,10 e $2,63 \mathrm{~m}^{3} \mathrm{~m}_{\text {linear }}{ }^{-1}$ (Tabela 5) respectivamente, para o coeficiente de enxurrada tabelado ( $c_{t}$ ) de 0,40 (Lombardi Neto et al., 1994). Quando se consideram os valores máximos de c obtidos nas medições das perdas de água das parcelas $\left(\mathrm{c}_{\mathrm{d}}\right)$, tem-se que as seções transversais do canal dos terraços foram menores, com médias de 0,278 e 0,153 $\mathrm{m}^{3} \mathrm{~m}_{\text {linear }}{ }^{-1}$ para os Ensaios 1 e 2 
Tabela 5. Espaçamento horizontal ( $E H$ ), chuva diária máxima ( $h$ ), coeficientes de enxurrada tabelado $\left(c_{t}\right)$ e determinado experimentalmente $\left(c_{d}\right)$ para o cálculo das áreas da seção transversal do canal do terraço ( $A t_{t}$ e $A t_{d^{\prime}}$, respectivamente para $\mathrm{C}_{\mathrm{t}}$ e $\left.\mathrm{c}_{\mathrm{d}}\right)$

\begin{tabular}{|c|c|c|c|c|c|c|}
\hline Tratamento & $\begin{array}{c}\text { EH } \\
\left(\mathrm{m}^{2} \mathrm{~m} \text { linear }^{-1}\right)\end{array}$ & $\begin{array}{c}\mathrm{h} \\
(\mathrm{m})\end{array}$ & $\begin{array}{c}c_{t}^{*} \\
-\end{array}$ & $\begin{array}{c}A t_{t} \\
\left(m^{3} \mathrm{~m} \mathrm{linear}^{-1}\right)\end{array}$ & $\mathrm{C}_{\mathrm{d}}{ }^{*}$ & $\begin{array}{c}A t_{d} \\
\left(m^{3} \mathrm{~m} \text { linear }^{-1}\right)\end{array}$ \\
\hline & \multicolumn{6}{|c|}{ Ensaio 1} \\
\hline $25 \mathrm{~m}$ & 25,0 & 0,105 & 0,40 & 1,05 & $0,082^{(1)}$ & 0,215 \\
\hline $50 \mathrm{~m}$ & 50,0 & 0,105 & 0,40 & 2,10 & $0,052^{(1)}$ & 0,273 \\
\hline $75 \mathrm{~m}$ & 75,0 & 0,105 & 0,40 & 3,15 & $0,044^{(1)}$ & 0,347 \\
\hline Média & 50,0 & 0,105 & 0,40 & 2,10 & 0,059 & 0,278 \\
\hline \multirow[t]{2}{*}{ CV (\%) } & 50,0 & & & 50,00 & 33,8 & 23,8 \\
\hline & \multicolumn{6}{|c|}{ Ensaio 2} \\
\hline $\mathrm{MA}-50 \mathrm{~m}$ & 50,0 & 0,105 & 0,40 & 2,10 & $0,028^{(2)}$ & 0,147 \\
\hline $\mathrm{MA}-75 \mathrm{~m}$ & 75,0 & 0,105 & 0,40 & 3,15 & $0,018^{(3)}$ & 0,142 \\
\hline $\mathrm{EC}-50 \mathrm{~m}$ & 50,0 & 0,105 & 0,40 & 2,10 & $0,031^{(1)}$ & 0,163 \\
\hline $\mathrm{EC}-75 \mathrm{~m}$ & 75,0 & 0,105 & 0,40 & 3,15 & $0,020^{(3)}$ & 0,158 \\
\hline Média & 62,5 & 0,105 & 0,40 & 2,63 & 0,024 & 0,153 \\
\hline CV (\%) & 23,1 & & & 23,1 & 25,7 & 6,3 \\
\hline
\end{tabular}

${ }^{*} c_{t}=c$ tabelado de acordo com Lombardi Neto et al., $1994 ; c_{d}=c$ determinado nos dias ${ }^{(1)} 24 / 12 / 2008,{ }^{(2)} 21 / 12 / 2008$ e ${ }^{(3)} 09 / 02 / 2009$

(Tabela 5). Apesar da elevada variação dos valores do coeficiente $\mathrm{c}_{\mathrm{d}}$, esses resultados mostram que, para as condições desse estudo, podem ser utilizados terraços com dimensões menores mesmo com aumento do espaçamento horizontal $(\mathrm{EH})$ entre eles, pois ocorre uma redução no volume de enxurrada das áreas agrícolas em sistema plantio direto.

\section{CONClusÕES}

1. No Latossolo onde foi desenvolvido o experimento, não houve produção de sedimentos no SPD, independente da direção de semeadura e do espaçamento entre terraços utilizados.

2. As perdas de água foram reduzidas em comprimentos de rampa de até $75 \mathrm{~m}$.

3. A direção de semeadura não influenciou o volume de perdas de água.

4. A distância entre terraços pode ser ampliada no sistema plantio direto para o solo e o declive estudados, independente da direção de semeadura.

\section{AgRAdECIMENTOS}

À Fundação de Amparo à Pesquisa do Estado de São Paulo (FAPESP), pela concessão da bolsa de mestrado ao primeiro autor.

\section{LITERATURA CITADA}

Albuquerque, A. W.; Lombardi Neto, F.; Srinivasan, V. S.; Santos, J. R. Manejo da cobertura do solo e de práticas conservacionistas nas perdas de solo e água em Sumé, PB. Revista Brasileira de Engenharia Agrícola e Ambiental, v.6, p.136-141, 2002.

Andrade, A. P.; Silva, I. F.; Diniz, E. J.; Santiago, R. D.; Oliveira, P. K. B. Perdas de solo e água por erosão num Latossolo VermelhoAmarelo, submetido a diferentes práticas agrícolas. Agropecuária Técnica, v.20, p.14-19, 1999.
Bertol, I.; Albuquerque, J. A.; Leite, D.; Amaral, A. J.; Zoldan Junior, W. A. Propriedades físicas do solo sob preparo convencional e semeadura direta em rotação e sucessão de culturas, comparadas às do campo nativo. Revista Brasileira de Ciência do Solo, v.28, p.155-163, 2004.

Bertol, I.; Cogo, N. P.; Levien, R. Erosão hídrica em diferentes preparos do solo logo após as colheitas de milho e trigo, na presença e ausência de resíduos culturais. Revista Brasileira de Ciência do Solo, v.21, p.409-418, 1997.

Bertol, I.; Cogo, N. P.; Schick, J.; Guadagnin, J. C.; Amaral, A. J. Aspectos financeiros relacionados às perdas de nutrientes por erosão hídrica em diferentes sistemas de manejo do solo. Revista Brasileira de Ciência do Solo, v.31, p.133-142, 2007a.

Bertol, O. J. Rizzi, N. E.; Bertol, I.; Roloff, G. Perdas de solo e água e qualidade do escoamento superficial associadas à erosão entre sulcos em área cultivada sob semeadura direta e submetida às adubações mineral e orgânica. Revista Brasileira de Ciência do Solo, v.31, p.781-792, 2007b.

Bertoni, J. Sistemas coletores para determinações de perdas por erosão. Bragantia, v.9, p.147-155, 1949.

Bertoni, J.; Lombardi Neto, F. Conservação do solo. 6.ed. São Paulo: Ícone, 2008. 355p.

Camara, R. K.; Klein, V. A. Escarificação em plantio direto como técnica de conservação do solo e da água. Revista Brasileira de Ciência do Solo, v.29, p.789-796, 2005.

Camargo, O. A. de; Moniz, A. C.; Jorge, J. A.; Valadares, J. M. A. S. Métodos de análise química, mineralógica e física de solos do Instituto Agronômico de Campinas. Campinas: Instituto Agronômico, 1986. 77p. Boletim Técnico, 106

Carvalho, D. F.; Cruz, E. S.; Pinto, M. F.; Silva, L. D. B.; Guerra, J. G. M. Características da chuva e perdas por erosão sob diferentes práticas de manejo do solo. Revista Brasileira de Engenharia Agrícola e Ambiental, v.13, p.3-9, 2009.

Carvalho, M. P.; Freddi, O. S.; Veronese Júnior, V. Critérios de classificação de chuva individual erosiva para o estado de São Paulo. Acta Scientiarum Agronomy, v.26, p.175-183, 2004.

Cassol, E. A.; Denardin, J. E.; Kochhann, R. A. Sistema plantio direto: Evolução e implicações sobre a conservação do solo e da água. In: Ceretta, C. A.; Silva, L. S.; Reichert, J. M. (ed.). Tópicos em ciência do solo. Viçosa: Sociedade Brasileira de Ciência do Solo, v.5, p.333-370, 2007. 
Ceretta, C. A.; Basso, C. J.; Flecha, A. M. T; Pavinato, P. S.; Vieira, F. C. B.; Mai, M. E. M. Manejo da adubação nitrogenada na sucessão aveia preta/milho, no sistema plantio direto. Revista Brasileira de Ciência do Solo, v.26, p.163-171, 2002.

Cogo, N.; Levien, R.; Schwarz, R. A. Perdas de solo e água por erosão hídrica influenciadas por métodos de preparo, classes de declive e níveis de fertilidade do solo. Revista Brasileira de Ciência do Solo, v.27, p.743-753, 2003.

Cogo, N. P.; Moldenhauer, W. C.; Foster, G. R. Soil loss reductions from conservation tillage practices. Soil Science Society American Journal, v.48, p.368-373, 1984.

Cogo, N. P.; Portela, J. C.; Amaral, A. J.; Trein, C. R.; Gilles, L.; Bagatini T.; Chagas, J. P. Erosão e escoamento superficial em semeadura direta efetuada com máquina provida de hastes sulcadoras, influenciados pela direção da operação de semeadura e pela cobertura superficial do solo. In: Congresso Brasileiro de Ciência do Solo, 31, 2007, Gramado. Resumos... Gramado: SBCS, 2007. CD-Rom

De Maria, I. C. Erosão e terraços em plantio direto. Boletim Informativo da Sociedade Brasileira de Ciência do Solo, v.24, p.17-22, 1999.

Denardin, J. E.; Kochhann, R. A.; Faganello, A; Sattler, A.; Manhago, D. D. "Vertical mulching" como prática conservacionista para manejo de enxurrada em sistema plantio direto. Revista Brasileira de Ciência do Solo v.32, p.2847-2852, 2008.

Eltz, F. L. F.; Cassol, E. A.; Guerra, M.; Abrão, P. U. R. Perdas de solo e água por erosão em diferentes sistemas de manejo e coberturas vegetais em solo São Pedro (Podzólico Vermelho Amarelo) sob chuva natural. Revista Brasileira de Ciência do Solo, v.8, p.245-249, 1984.

EMBRAPA - Empresa Brasileira de Pesquisa Agropecuária Centro Nacional de Pesquisa de Solos. Sistema Brasileiro de Classificação de Solos. 2.ed., Rio de Janeiro: Embrapa Solos, 2006. 306p.

Foster, G. R.; Johnson, C. B.; Moldenhauer, W. C. Hydraulics of failure of unanchored cornstalk and wheat straw mulches for erosion control. Transactions of the American Society of Agricultural Engineers, v.25, p.940-947, 1982.

Franchini, J. C.; Hoffmann-Campo, C. B.; Torres, E.; Miyazawa, M.; Pavan, A. Organic composition of green manure during growth and its effect on cation mobilization in an acid Oxisol. Communications in Soil Science and Plant Analysis, v.34, p.2045-2058, 2003.

Garcia, S. M.; Righes, A. A. Vertical mulching e manejo da água em semeadura direta. Revista Brasileira de Ciência do Solo, v.32, p.833-842, 2008.

Leite, D.; Bertol, I.; Guadagnin, J. C.; Santos, E. J.; Ritter, S. R. Erosão hídrica em um Nitosolo Háplico submetido a diferentes sistemas de manejo sob chuva simulada. I - Perdas de água e solo. Revista Brasileira de Ciência do Solo, v.28, p.1033-1044, 2004.
Lombardi Neto, F.; Belinazzi Júnior, R.; Lepsch, I. F.; Oliveira, J. B.; Bertolini, D.; Galeti, P. A.; Drugowich, M. I. Terraceamento agrícola. In: Bertolini, D.; Lombardi Neto, F.; Lepsch, I. F.; Oliveira, J. B.; Drugowich, M. I.; Andrade, N. O.; Galeti, P. A.; Belinazzi Junior, R.; Dechen, S. C. F. Manual técnico de manejo e conservação de solo e água. Campinas: CATI, 1994. v.4, p.11-35. Manual Técnico, 41

Mello, E. L.; Bertol, I.; Zaparolli, A. L. V.; Carrafa, M. R. Perdas de solo e água em diferentes sistemas de manejo de um Nitossolo Háplico submetido à chuva simulada. Revista Brasileira de Ciência do Solo, v.27, p.901-909, 2003.

Morais, L. F. B.; Cogo, N. P. Comprimentos críticos de rampa para diferentes manejos de resíduos culturais em sistema semeadura direta em um Argissolo Vermelho da Depressão Central (RS). Revista Brasileira de Ciência do Solo, v.25, p.1041-1051, 2001.

Panachuki, E.; Alves Sobrinho, T.; Vitorino, A. C. T.; Carvalho, D. F. de.; Urchei, M. A. Parâmetros físicos do solo e erosão hídrica sob chuva simulada, em área de integração agricultura-pecuária. Revista Brasileira de Engenharia Agrícola e Ambiental, v.10, p.261-268, 2006.

Raij, B. van; Andrade, J. C.; Cantarella, H.; Quaggio, J. A. Análise química para avaliação da fertilidade de solos tropicais. Campinas: Instituto Agronômico, 2001. 285p.

Rolim, G. S.; Camargo, M. B. P. de; Lania, D. G; Moraes, J. F. de. Classificação climática de Köppen e de Thornthwaite e sua aplicabilidade na determinação de zonas agroclimáticas para o Estado de São Paulo. Bragantia, v.66, p.711-720, 2007.

Salton, J. C.; Hernani, L. C.; Fontes, C. Z. Sistema Plantio Direto - O produtor pergunta, a Embrapa responde. Dourados: Embrapa- CPAO, Brasília: Embrapa SPI, 248p., 1998. Coleção 500 Perguntas 500 Respostas

Schick, J.; Bertol, I.; Batistela, O.; Balbinot Jr., A. A. Erosão hídrica em Cambissolo Húmico alumínico submetido a diferentes sistemas de preparo e cultivo do solo: I. Perdas de solo e água. Revista Brasileira de Ciência do Solo, v.24, p.427-436, 2000.

Seganfredo, M. L.; Eltz, F. L. F.; Brum, A. C. R. Perdas de solo, água e nutrientes por erosão em sistemas de culturas em plantio direto. Revista Brasileira de Ciência do Solo, v.21, p.287-291, 1997.

Silva, L. S.; Camargo, F. A. O.; Ceretta, C. A. Composição da fase sólida orgânica do solo. In: Meurer, E. J. Fundamentos de química do solo. Porto Alegre: Gênesis, 2000. p.45-62.

Tormena, C. A.; Vidigal Filho, P. S.; Gonçalves, A. C. A.; Araújo, M. A.; Pinto, J. C. Influência de diferentes sistemas de preparo do solo nas propriedades físicas de um Latossolo Vermelho distroférico. Revista Brasileira de Engenharia Agrícola e Ambiental, v.8, p.65-71, 2004.

Vieira, S. R.; Lombardi Neto, F.; Burrows, I. T. Mapeamento da chuva diária máxima provável para o Estado de São Paulo. Revista Brasileira de Ciência do Solo, v. 15, p.93-98, 1991.

Wischmeier, W. H.; Smith, D. D. Predicting rainfall erosion losses: a guide to conservation planning. Washington: USDA - Agricultural Research, 1978. 58p. Agricultural Handbook, 537 